\title{
Progress in the Theory of Quadratic Indeterminate Analysis
}

\author{
Vinod Mishra ${ }^{1}$ \\ Department of Mathematics, SantLongowal Inst. of Engineering and Technology \\ Longowal-148106 (Punjab). India
}

\begin{abstract}
Theory of indeterminate analysis of second degree in India goes back to Brahmagupta (ca. 628 AD). This paper is intended to present the work in the areas of indeterminate analysis of second degree till seventeenth century. Examples of significance and comparative studies, apart from modern development in the field, have been included. Finally, matrix equivalent solution of Nārāyaṇa rule is evolved.
\end{abstract}

Key Words. Quadratic indeterminate analysis; cyclic method; continued fraction; principle of composition

\section{INTRODUCTION}

The problems of determining solutions of algebraic equations (second and higher degrees) of indeterminate nature are called Diophantus analysis, after the Greek mathematician Diophantus of Alexandria ( ${ }^{\text {rd }}$ century AD).

A part of his work Arithmetica containing indeterminate equation of the type: $26 x^{2}+1=y^{2}, 30 x^{2}+1=y^{2}$, was studied by Fermat in 1657. Fermat is credited to have initiated the study in Europe.

Euler in 1732 and Lagrange in 1767 gave new turn to the solutions of equations which was based on continued fraction.

Incidentally, Euler referred to it as the Pell's equation (J. Pell, 1611-1685 AD), but it has no historical justification whatever. There is no contribution of Pell to this topic except to find the solution of $2 x^{2}+1=y^{2}$ by geometric means..

Noticeable that the Cattle problem of Archimedes (3rd century BC) involving equation $4729494 x^{2}+1=y^{2}$ provides first example of what the so-called Pell's equation.

The term vargaprakrti or krtiprakrti (square nature) has been introduced by ancient Indian mathematicians to designate an equation of the type

$N x^{2}+c=y^{2}$,

Where

$\mathrm{N}$ - a non-square number, is called multiplier (prakrti, guna, gunika etc.)

$c$ - a positive or negative integer, is termed as interpolator (kșepaka, prașepaka, prașepa, kșepa etc.). When $c$ negative is also called śodhaka (subtractive).

$x \& y$ - the lesser root (harașvamula, kanișthapada)or first root (ādyamula) and greater (jyeștha or vṛhata) root or second root respectively.

Notice that the solution $N x^{2}+1=y^{2}$ is always possible while $N x^{2}-1=y^{2}$ may not have integer solution.

After Brahmagupta (Brahmsphutasiddhānta, c. 628 AD), the further refinements, clarifications, extensions were made by subsequent mathematicians, namely Śripati (Siddhāntaśekhara, c. 1039), Acārya Jayadeva (fl. Before 1073, his work is quoted and explained with illustration in the Sundari, a commentary on the Laghu-Bhāskariya of Bhāskara I written in 1073 by Udayadayadivakara), Bhāskara II (Līlāvatī and Bījaganita, ca 1150), Nārāyaṇa (Ganitakaumudī and Bijaganita, 1356) and others including several commentaries.

The aim of scholars namely Brahmagupta and Śripati was to obtain solutions of equation

$$
N x^{2}+1=y^{2}
$$

\footnotetext{
${ }^{1}$ Corresponding Author: vinodmishra.2011@ rediffmail.com
} 
In positive integers.

They, however, discovered the following

Lemma 1.An integral solution of

$N x^{2}+k=y^{2}$

can always be found if $k$ equals $\pm 1, \pm 2$ or \pm 4 .

Lemma2.From an integral solution of an auxiliary equation (3), where $k= \pm 1, \pm 2$ or \pm 4 , integral solution of equation (2) can always be deduced.

Brahmagupta and others had no method other than the trial to solve equation (3) where $k= \pm 1, \pm 2$ or \pm 4 .

BhāskaraII removes this deficiency (which is needed in harder cases where trial fails) by providing a method called cakravāla or cyclic method; cakravāla (circle) because of its iterative character. "It proceeds in a circle, the same set of operations being applied again and again in a continuous round" and it reveals thereby a resemblance to the continued fraction process of Euler.

Professor Clas-ol of Selenius writes: Since the cakravāla method, and the other Hindu methods for solving Jayadeva-Bhāskara equation

$$
N x^{2}+1=y^{2},
$$

did not occur in China at all, it must be regarded as purely Indian creation.

Hankel's remark is significant in the sense that 'the cakravāla method was the absolute climax of old Indian science, and so of all oriental mathematics'.

It is accepted fact that the cakravāla method -anticipated the European methods by more than a thousand years.

Moreover, Diophantus and his contemporaries were interested in getting just one solution whereas principle of composition (Bhāvanā) of Brahmagupta gives infinite number of solutions.

\subsection{Principle of Composition (Bhāvanāa) Due to Brahmagupta}

Let $N$ be a positive integer. If two integral solutions of the equation

$$
\begin{aligned}
& N x^{2}+c_{1}=y^{2} \\
& N x^{2}+c_{2}=y^{2}
\end{aligned}
$$

For example if $(p, q)$ and $\left(p^{\prime}, q\right)$, then $(p \dot{q} \pm p q, q \dot{q} \pm N p \dot{p})$ is also a solution of

$$
N x^{2}+c_{1} c_{2}=y^{2}
$$

If we take $(p, q)=\left(p^{\prime}, q\right)=(a, b)$ in this Lemma, then $\left(2 a b, b^{2}+N a^{2}\right)$ is a solution of

$$
N x^{2}+c=y^{2},
$$

Where $c_{1}=c_{2}=c$.

Lemma3. If two solutions of equation are known $N x^{2}+1=y^{2}$, then any number of other solutions can be found using principle of composition.

Lemma4. Dividing the integral solution of $N x^{2}+c=y^{2}$, by c the rational solution $\left(\frac{x}{c}, \frac{y}{c}\right)$ of $N x^{2}+1=y^{2}$, is obtained.

\subsection{Samāsa-Bhāvanā/ Antra-Bhāvanā/ Tulya-Bhāvanā}

Bhāskara II(Bỉjaganita, v. 2-4):

'Set down successively the lesser root (hrasva), greater root (jyestha) and interpolator (kșepaka), and below them should be set down in order the same or an another (set of similar quantities). From them by the principle of

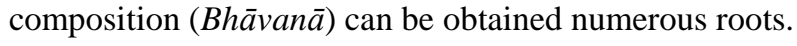


American Research Journal of Mathematics, Volume 1, Issue 4, 2015

ISSN 2378-704X

Therefore, the principle of composition will be explained here. (Find) the two cross products (vajrabhyasa) of the two lesser and the two greater roots; their sum is a lesser root. In that (equation) the interpolator will be the product of the two previous interpolators. Again the difference of the two cross-products in a lesser root. Subtract the product of the lesser roots multiplied by the prakrti from the product of the two greater roots; (the difference) will be greater root. Here also the interpolator is the product of the two (previous) interpolators'.

These results may be conveniently expressed in a tabular form as follows:

Samāsa-Bhāvanā(additive composition)

\begin{tabular}{|l|l|l|l|}
\hline Prakṛt & Harasva & Harasva & Ksepa \\
\hline \multirow{4}{*}{$\mathrm{N}$} & $a_{1}$ & $b_{1}$ & $c_{1}$ \\
\cline { 2 - 5 } & $a_{2}$ & $b_{2}$ & $c_{2}$ \\
\cline { 2 - 5 } & $a_{1} b_{2}+a_{2} b_{1}$ & $b_{1} b_{2}+N a_{1} a_{2}$ & $c_{1} c_{2}$ \\
\hline
\end{tabular}

Antra-Bhāvanā (subtractive composition)

\begin{tabular}{|l|l|l|l|}
\hline Prakrt & Harasva & Harasva & Kșepa \\
\hline \multirow{4}{*}{$\mathrm{N}$} & $a_{1}$ & $b_{1}$ & $c_{1}$ \\
\cline { 2 - 4 } & $a_{2}$ & $b_{2}$ & $c_{2}$ \\
\cline { 2 - 4 } & $a_{1} b_{2}-a_{2} b_{1}$ & $b_{1} b_{2}-N a_{1} a_{2}$ & $c_{1} c_{2}$ \\
\hline
\end{tabular}

Tulya-Bhāvanā(composition of equals)

\begin{tabular}{|l|l|l|l|}
\hline Prakrt & Harasva & Harasva & Kșepa \\
\hline $\mathrm{N}$ & $a_{1}$ & $b_{1}$ & $c_{1}$ \\
\cline { 2 - 4 } & $\boldsymbol{a}_{\mathbf{1}}$ & $b_{1}$ & $c_{1}$ \\
\cline { 2 - 4 } & $2 a_{1} b_{1}$ & $b_{1}^{2}+N a_{1}^{2}$ & $c_{1}^{2}$ \\
\hline
\end{tabular}

\section{VARIOUS METHODS AND EQUATIONS}

\subsection{Another Method can be Explored}

Let $\left(q_{n}, p_{n}\right), n=0,1,2, \ldots, n$ be solutions of $y^{2}-N x^{2}=1$.

The equation can be rewritten as $\left(q_{0}-N p_{0}\right)\left(q_{0}+N p_{0}\right)=1$.

Also $\left(q_{n-1}-\sqrt{N} p_{n-1}\right)\left(q_{n-1}-\sqrt{N} p_{n-1}\right)=1$.

Multiplying

$\left(q_{0} q_{n-1}+N p_{0} y_{n-1}\right)^{2}-N\left(p_{0} q_{n-1}+q_{0} p_{n-1}\right)^{2}=1$.

This generates recurrence relation

$q_{n}=q_{0} q_{n-1}+N p_{0} p_{n-1}, p_{n}=p_{0} q_{n-1}+q_{0} p_{n-1}$.

Eliminating $q_{n-1}, p_{n-1}=p_{0} q_{n}-q_{0} p_{n}$. That is, $q_{n}=\frac{1}{y_{0}}\left[p_{n-1}+q_{0} p_{n}\right]$.

Eliminating $p_{n-1}, q_{n-1}=q_{0} q_{n}-N p_{0} p_{n}$. That is $p_{n}=\frac{1}{N p_{0}}\left[q_{0} q_{n}-q_{n-1}\right]$.

Substituting these in recurrence relation

$q_{n}=2 q_{0} q_{n-1}-q_{n-2}$ and $p_{n}=p_{n-2}+2 q_{0} p_{n-1}, n \geq 2$

Following Nārāyaṇa, nth convergent of $\sqrt{N} \approx \frac{p_{n}}{q_{n}}$ for $n$ sufficiently large. 


\section{Error estimation Proposition [18]:}

Let $N>0$ be a non-square integer such that $N=A_{1}^{2}+r$, where $A_{1}$ is the largest positive integer and $|r|$ the smallest integer. Then

$$
A_{i}=\frac{N d_{i-1}^{2}+n_{i-1}^{2}}{2 d_{i-1} n_{i-1}}, i=1,2,3, \ldots . ., n
$$

are the successive convergents to the series

$$
\sqrt{N}=A_{1}+\frac{r}{m}+\sum_{i=3}^{n} \frac{N d_{i-1}^{2}-n_{i-1}^{2}}{2 d_{i-1} n_{i-1}} .
$$

Where $d_{i-1}$ and $n_{i-1}$ stand for the sum of denominator and numerator up to $(i-1)$ terms respectively and $m$ for a positive integer.

Since $\left|\sqrt{N}-A_{i}\right|=R_{i}$. Therefore, $\left|\sqrt{N}-A_{1}\right|=R_{1}$.

$$
\begin{aligned}
& \left|\sqrt{N}-A_{2}\right|=R_{2}=A-\frac{R_{1}^{2}}{2 A_{1}}=\frac{K}{2 A_{1}}, K=2 A A_{1}-R_{1}^{2} \cdot ; A=r\left(\frac{1}{2 A_{1}}-\frac{1}{m}\right), m>r ; r=N-A_{1}^{2} \\
& \left|\sqrt{N}-A_{3}\right|=R_{3}=-\frac{R_{2}}{2 A_{2}}=-\frac{K}{2 A_{1} A_{2}} . \\
& \left|\sqrt{N}-A_{4}\right|=R_{4}=-\frac{R_{3}}{2 A_{3}}=(-1)^{2} \frac{K}{2^{2} A_{1} A_{2} A_{3}} .
\end{aligned}
$$

Proceeding in this way

$$
\begin{aligned}
\left|\sqrt{N}-A_{i}\right| & =R_{i}=-\frac{R_{i-1}}{2 A_{3}}=(-1)^{i-2} \frac{K}{2^{i-1} A_{1} A_{2} A_{3} \ldots A_{i-1}}<(-1)^{i-2} \frac{K}{2^{i-2} A_{i-1}^{i-1}}, i>2 \\
& =O\left(\frac{1}{A_{i-1}^{i-1}}\right) .
\end{aligned}
$$

\subsection{Method of Finding Rational Roots of $N x^{2}+1=y^{2}$}

Siddhāntaśekharaxiv.32 states the following rule:

"Divide twice an optional number by the difference between the square of that optional number and the prakrti. This (quotient) will be the lesser root (of a square nature) when unit id the additive. From that (follows) the greater root".

Rationale. Choose $\mathrm{p}$ a positive integer such that $p^{2}-N= \pm q$. Let $x=\frac{2 p}{q}$.

Now $4 N p^{2}+q^{2}=4\left(p^{2} \mp q\right) p^{2}+q^{2}=\left(2 p^{2} \mp q\right)^{2}$.

$$
\therefore y^{2}=N\left(\frac{2 p}{q}\right)^{2}+1=\left\{\frac{2 p^{2} \mp q}{q}\right\}^{2} \text {. }
$$

This implies $y=\frac{2 p^{2}}{q} \mp 1$.

Special case. For $q=1($ or 2$)$ or $\frac{p}{q}$ an integer, the above rule yields integral solution.

The rational solution can also be given as $x=\frac{k}{B h-A b}, y=\frac{A h-B b}{B h-A b}, h^{2}=b^{2}+k^{2}$, where $\mathrm{b}, \mathrm{k}$ and $\mathrm{h}$ are respectively the base, upright and hypotenuse of a right angled triangle; A,B being two numbers such that $A^{2}-B^{2}=N$. This has been found in commentary on Pătiganita. The solution is unique and is the most general rational solution. The solutions given by Brahmagupta (c. 628 AD), Śripati (1039 AD), Bhāskara II (1150AD), Nārāyaṇa (1357AD), Jnānarāja (1503AD), Kamlākara, and also by Wallis and W. Browncker (c.1657AD) are all deductible from it. 
Śripati(c. 1039AD) (Siddhāntaśekhara xiv, v.33) gives the following rule for rational solution:"Unity is the lesser root. Its square multiplied by the prakrti is increased or decreased by the prakrti combined with an (optional) whose square-root will be greater root. From them will be obtained two roots by the principle of composition".

That is, if $\mathrm{m}$ be the rational number optionally chosen, $N 1^{2}+\left(m^{2}-N\right)=m^{2}$. By Tulya Bhāvana $N(2 m)^{2}+\left(m^{2}-N\right)^{2}=\left(m^{2}+N\right)^{2}$. Hence $x=\frac{2 m}{m^{2}-N}, y=\frac{m^{2}-N}{m^{2}-N}$. This method was rediscovered in Europe by

Brouncker in 1657.

Remark. This rule is not useful when $N=41,61,67,97,103$, etc.

2.3. The Equation $M n^{2} x^{2} \pm c=y^{2}$

Rule GK13 [8]. "Divide the multiplier (of a square nature) by any arbitrary square number, so that, no remainder is left (after division). Take the quotient as the multiplier of another square nature. The lesser root (of the reduced equation), divided by the square-root of the divisor, will be the lesser-root (of the original equation)".

Let $a$ be the lesser root of the transformed equation $M z^{2} \pm c=y^{2}, z=n x$. The lesser root of the given equation will be $a / n$ while the greater roots of the both will remain the same.

\subsection{The equation $M^{2} x^{2} \pm c=y^{2}$}

Rule GK14 [8]. "The interpolator, divided by an optional number, is set down at two places. The quotient is diminished (at one place and) increased (at the other) by that (optional number and then) halved. The former is divided by the square-root of the multiplier. These are the lesser and greater roots, in order".

Bhāskara II has given solution for positive ksepa only. Let $k$ be an optional number including 1 , then $x=\frac{1}{2 M}\left( \pm \frac{c}{k}-k\right), y=\frac{1}{2}\left( \pm \frac{c}{k}+k\right)$.

For rationale refer to [8]

Another Method

Rewrite as $(y-n x)(y+n x)=M$ for kșepa positive and $(y-n x)(y+n x)=M$ for kṣepa negative. Let $M=m_{1} \cdot m_{2}, m_{1}<m_{2}$ so that $y-n x=m_{1}, y+n x=m_{2}$. Solving $x=\frac{m_{2}-m_{1}}{2 n}, y=\frac{m_{2}+m_{1}}{2}$. For kșepa negative $x=\frac{m_{2}+m_{1}}{2 n}, y=\frac{m_{2}-m_{1}}{2}$.

2.5. The Equation $N x^{2} \pm c=y^{2}$

Rule GK15-16 [8]. "When the additive or subtractive is greater than unity, the (two) roots should be determined by one's own intelligence. Then by the principle of composition of the roots with the additive unity, an infinite number of roots (can be obtained). Persons having no intelligence, have no knowledge of mathematics. They should be told the whole of mathematics by one's own intelligence".

Let $(a, b)$ be the solution of $N x^{2}+c=y^{2}$ and $(p, q)$ be the solution of $N x^{2} \pm 1=y^{2}$. Then by the principle of composition $(b p \pm a q, b p \pm N a p)$ will be the solution of $N x^{2} \pm c=y^{2}$.

\subsection{Chakravāla Method of Bhāskara II[(Bījagaṇita)[2, pp. 162-163]}

"Considering the lesser root, greater root and interpolator (of a square nature) as the dividend, addend and divisor (respectively of a pulveriser), the (indeterminate) multiplier of it should be so taken as will make the residue of the prakrti diminished by the square of that multiplier or the latter minus the prakrti (as the case may be) the least. That residue divided by the (original) interpolator is the interpolator (of a new square-nature); it should be reversed in sign in case of subtraction from the prakrti. The quotient corresponding to that value of the multiplier is the (new) 


\section{American Research Journal of Mathematics, Volume 1, Issue 4, 2015 \\ ISSN 2378-704X}

lesser root; hence the greater root. The same process should be followed repeatedly putting aside (each time) the previous roots and the interpolator. This process is called cakravāla (or the cyclic method). By this method there will appear two integral roots corresponding to an equation with $\pm 1, \pm 2$ or \pm 4 as interpolator. In order to device integral roots corresponding to an equation with the additive unity from those of the equation with interpolator \pm 2 or \pm 4 the principle of composition (should be applied)".

Lemma 5: If

$N a^{2}+k=b^{2}$

Then for any positive integer $m$

$N(a m+b)^{2}+\left(m^{2}-N\right) k=(b m+N a)^{2}$, i.e.

$N\left(\frac{a m+b}{k}\right)^{2}+\frac{m^{2}-N}{k}=\left(\frac{b m+N a}{k}\right)^{2}$

is obtained by composing $N 1^{2}+\left(m^{2}-N\right)=m^{2}$ and (8) by Samāsa Bhāvanāa.

Now to find solution of $N x^{2}+1=y^{2}$ we proceed with (8) and obtain (9). Let $\frac{a m+b}{k}=a_{1}, \frac{b m+N a}{k}=b_{1}$, $\frac{m^{2}-N}{k}=k_{1}$. The value of $m$ is obtained from pulveriser $a m+b=k a_{1}$ and is chosen so that $m^{2}-N$ is numerically the least.

Bhāskara II gives the following two theorems:

Theorem1. When $a_{1}$ is an integer, $b_{1}$ and $k_{1}$ are also integers, so we obtain from (II)

$N a_{1}^{2}+k_{1}=b_{1}^{2}$

If $k_{1}= \pm 1, \pm 2$ or \pm 4 , then (10) is a suitable auxiliary equation. Otherwise, we repeat the above process with (10) as we did with (8) and obtain, say $N a_{2}{ }^{2}+k_{2}=b_{2}{ }^{2}$.

Theorem2. After a finite number of repetitions, we obtain a suitable equation $N \alpha^{2}+l=\beta^{2}$, where $l= \pm 1, \pm 2$ or \pm 4 . And by process of Bhāvanā such an equation easily leads to $N x^{2}+1=y^{2}$.

Illustrations (Büjagaṇita,v.76)

$$
61 x^{2}+1=y^{2} \text {. Solution: }(226153980,1766319049)
$$

$$
67 x^{2}+1=y^{2} \text {. Solution: }(5967,48842)
$$

Note that the problem (i) was one of the challenging problems proposed by French mathematician, Fermat, in 1657 to Frenicle and other fellow mathematicians in Europe as challenge. None of them succeeded in solving the equation in integers. Euler solved it in 1732 with the help of continued fraction.

The cakravāla method certainly involves fewer steps than the Euler method

The cyclic method was reproduced by Nārāyaṇa Pạ̣dita (Ganitakaumudī)

i) $\quad 97 x^{2}+1=y^{2}$. Solution: $(6377352,62809633)$

ii) $\quad 103 x^{2}+1=y^{2}$. Solution: $(22419,227528)$

Remark. Majumdar [11]. Changing the suffices

$a_{n+1}=\frac{a_{n} m+b_{n}}{k_{n}}, b_{n+1}=\frac{b_{n} m+N a_{n}}{k_{n}}, k_{n+1}=\frac{m^{2}-N}{k_{n}}$ 
American Research Journal of Mathematics, Volume 1, Issue 4, 2015

ISSN 2378-704X

Letting $a_{n}=q_{n}, b_{n}=p_{n}$

$\frac{p_{n+1}}{q_{n+1}}=\frac{p_{n} m+N q_{n}}{q_{n} m+p_{n}}$

This implies $N q_{n} q_{n+1}-p_{n} p_{n+1}=n\left(q_{n} p_{n+1}-q_{n} p_{n+1}\right)=n(-1)^{i+1}$.

\section{Conjecture:}

Find the other solutions of $7 x^{2}+9=y^{2}$, the three solutions known are $(1,4),(9,24),(65,172)$.

Example1 (LV). $61 x^{2}+1=y^{2}$.

Table1. Simulation Result for Exl

\begin{tabular}{|c|c|c|c|c|}
\hline Steps & $m_{i}$ & $x_{i}$ & $k_{i}$ & $y_{i}$ \\
\hline 0 & & 1 & 3 & 8 \\
\hline 1 & 7 & 5 & -4 & 39 \\
\hline 2 Samāsa Bhāvanā & & 195 & 4 & 1523 \\
\hline 3 Antra Bhāvanā & & 3805 & -1 & 29718 \\
\hline 4 Samāsa Bhāvanā & & 226153980 & 1 & 1766319049 \\
\hline
\end{tabular}

Example2 (CF). $61 x^{2}+1=y^{2}$.

Table2. Simulation Result for Ex2

\begin{tabular}{|l|l|l|l|l|l|}
\hline Steps & $a_{i}$ & $k_{i}$ & $r_{i}$ & $y_{i}$ & $x_{i}$ \\
\hline 0 & 7 & 1 & 0 & 7 & 1 \\
\hline 1 & $1 *$ & 12 & 7 & 8 & 1 \\
\hline 2 & 4 & 3 & 5 & 39 & 5 \\
\hline 3 & 3 & 4 & 7 & 125 & 16 \\
\hline 4 & 1 & 9 & 5 & 164 & 1 \\
\hline 5 & 2 & 5 & 4 & 453 & 58 \\
\hline 6 & 2 & 5 & 6 & 1070 & 137 \\
\hline 7 & 1 & 9 & 4 & 1523 & 195 \\
\hline 8 & 3 & 4 & 5 & 5639 & 722 \\
\hline 9 & 4 & 3 & 7 & 24079 & 3083 \\
\hline 10 & 1 & 12 & 5 & 29718 & 3805 \\
\hline 11 & $14 *$ & 1 & 7 & 440131 & 56353 \\
\hline
\end{tabular}

Example3 (GK). $97 x^{2}+1=y^{2}$.

Table3. Simulation Result for Ex3

\begin{tabular}{|l|l|l|l|l|}
\hline Steps & $m_{i}$ & $x_{i}$ & $k_{i}$ & $y_{i}$ \\
\hline 0 & & 1 & 3 & 10 \\
\hline 1 & 11 & 7 & 8 & 69 \\
\hline 2 & 13 & 20 & 9 & 197 \\
\hline 3 & 14 & 53 & 11 & 522 \\
\hline 4 & 8 & 86 & -3 & 847 \\
\hline 5 & 10 & 569 & -1 & 5604 \\
\hline 6 Samāsa Bhāvanā & & 6377352 & 1 & 62809633 \\
\hline
\end{tabular}

Example4 (CF). $97 x^{2}+1=y^{2}$.

Table4. Simulation Results for Ex4 
American Research Journal of Mathematics, Volume 1, Issue 4, 2015

\section{ISSN 2378-704X}

\begin{tabular}{|l|l|l|l|l|l|}
\hline Steps & $a_{i}$ & $k_{i}$ & $r_{i}$ & $y_{i}$ & $x_{i}$ \\
\hline 0 & 9 & 1 & 0 & 9 & 1 \\
\hline 1 & $1^{*}$ & 16 & 9 & 10 & 1 \\
\hline 2 & 5 & 3 & 7 & 59 & 6 \\
\hline 3 & 1 & 11 & 8 & 69 & 7 \\
\hline 4 & 1 & 8 & 3 & 128 & 13 \\
\hline 5 & 1 & 9 & 5 & 197 & 20 \\
\hline 6 & 1 & 9 & 4 & 325 & 33 \\
\hline 7 & 1 & 8 & 5 & 522 & 53 \\
\hline 8 & 1 & 11 & 3 & 847 & 86 \\
\hline 9 & 5 & 3 & 8 & 4757 & 483 \\
\hline 10 & 1 & 16 & 7 & 5604 & 569 \\
\hline 11 & $18^{*}$ & 1 & 9 & 105629 & 10725 \\
\hline
\end{tabular}

\subsection{Continued Fraction and Convergents of $\sqrt{N}$}

Let $\sqrt{N}$ be written as a rational number $\frac{a}{b}$. Further, if $\frac{p_{1}}{q_{1}}, \frac{p_{2}}{q_{2}}, \ldots ., \frac{p_{n}}{q_{n}}$ be the successive convergents, then

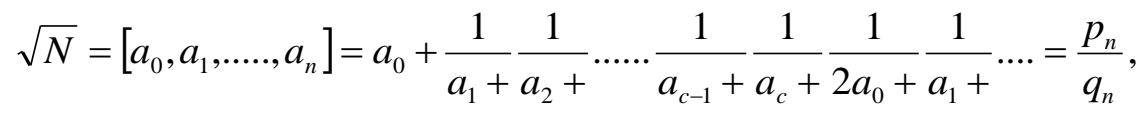

where

$$
\frac{p_{0}}{q_{0}}=a_{0}, \frac{p_{1}}{q_{1}}=a_{0}+\frac{1}{a_{1}}, \frac{p_{2}}{q_{2}}=a_{0}+\frac{1}{a_{1}+\frac{1}{a_{2}}}, \ldots \ldots ., \frac{p_{n}}{q_{n}}=\frac{a}{b} .
$$

$a_{0} \geq 0, a_{n} \geq 1(n=1,2,3 \ldots)$ is called the simple continued fraction. $c$ is the number of elements in the recurring cycle. The cakravāla process can be explained with the help of regular continued fraction expansion of $\sqrt{N}$. Once compared $h_{n}$ stands for interpolator, $q_{n}$ the lesser root and $p_{n}$ the greater root.

Let

Let $a_{0}=\lfloor\sqrt{N}\rfloor a_{0}<\sqrt{N}<a_{0}+1$. Then $a_{0}$ is called integral part of irrational number $\sqrt{N}$. The fractional part $\sqrt{N}-a_{0}$ is such that $0<\sqrt{N}-a_{0}<1$, i.e. $0<\frac{N-a_{0}{ }^{2}}{\sqrt{N}+a_{0}}<1 . \sqrt{N}-a_{0}=\frac{N-a_{0}{ }^{2}}{\sqrt{N}+a_{0}}$, i.e. $\sqrt{N}=a_{0}+\frac{N-a_{0}{ }^{2}}{\sqrt{N}+a_{0}}=a_{0}+\frac{1}{\delta_{1}}$, where $\delta_{1}=\frac{\sqrt{N}+a_{0}}{N-a_{0}^{2}}>1$.

Define $\delta_{1}=\frac{\sqrt{N}+a_{0}}{N-a_{0}^{2}}=\frac{\sqrt{N}+a_{0}}{h_{0}}=a_{1}+\frac{1}{\delta_{2}}, a_{1}=\left[\delta_{1}\right]$ $\delta_{2}=\frac{\sqrt{N}+r_{0}}{h_{1}}=a_{2}+\frac{1}{\delta_{3}}, a_{2}=\left[\delta_{2}\right]$

And so on $\delta_{n}=\frac{\sqrt{N}+r_{n-2}}{h_{n-1}}=a_{n}+\frac{1}{\delta_{n+1}}, n=2,3, \ldots$

After a certain stage, the partial quotients recur indefinitely in the same order. We say that CF of $\sqrt{N}$ its periodic or cyclic. The number of partial quotients involved is termed as its range $(c)$. 
The above expression in compact form is written as $\sqrt{N}=\left[a_{0}, a_{1}, a_{2}, \ldots \ldots, a_{c}{ }^{*}\right]$. By property of symmetry, we find the expansion in the form $\sqrt{N}=\left[a_{0}, a_{1}, a_{2}, \ldots \ldots, a_{2,} a_{1}, 2 a_{0}{ }^{*}\right]$ That is the periodic part $\left[a_{1}, a_{2,}, \ldots . ., a_{c-1,}, 2 a_{0}{ }^{*}\right]$ has the property of symmetry $a_{c}=2 a_{0}, a_{k}=a_{c-k}, k=1,2, \ldots . ., c-1$.

Let $a_{n}, b_{n}$ and $h_{n}$ be defined by the relations

$\frac{\sqrt{N}+b_{n}}{h_{n}}=a_{n}+\frac{\sqrt{N}-b_{n+1}}{h_{n}}=a_{n}+\frac{h_{n+1}}{\sqrt{N}-b_{n-1}}$

Such that $a_{n}<\frac{\sqrt{N}+b_{n}}{h_{n}}=a_{n+1}$

$b_{n+1}<a_{n} h_{n}-b_{n}$ And $h_{n} h_{n+1}=N-b_{n+1}^{2}$

Notice that if $(-1)^{n+1} h_{n}=M$, then $\left(q_{n}, p_{n}\right)$ is a solution of $N x^{2}+M=y^{2}$ for some $\mathrm{n}$, where $p_{n} / q_{n}$ is the nth convergent of $\sqrt{N}$.

$$
\begin{aligned}
& p_{n}=a_{n} p_{n-1}+p_{n-2}, n>2 \\
& q_{n}=a_{n} q_{n-1}+q_{n-2}, n>2 \\
& p_{0}=a_{0}, q_{0}=1 \\
& p_{1}=a_{0} a_{1}+1, q_{1}=a_{1}
\end{aligned}
$$

Solutions of equation are $\left(q_{t c}, p_{t c}\right)$ when $c$ is even and $\left(q_{2 t c}, p_{2 t c}\right)$ when $c$ is odd. Solutions of $N x^{2}-1=y^{2}$ are $\left(q_{(2 t-1) c}, p_{(2 t-1) c}\right)$ when $c$ is odd. No solution is possible when $c$ is even. Notice that the convergents satisfy the relation

$$
p_{n} q_{n-1}-q_{n} p_{n-1}=(-1)^{n-1}, n=1,2, \ldots
$$

Table-5

\subsection{Comparison of Regular (Continued) Vs Semi-Regular (Cakravāla) Algorithm}

\section{Table5.}

\begin{tabular}{|l|l|l|l|l|l|l|l|l|}
\hline Sr No & \multicolumn{9}{l}{ Convergents for $\sqrt{97}$} & \multicolumn{3}{l|}{ Convergents for $\sqrt{61}$} \\
\hline & CF & $k_{i}$ & Cakravāla & $k_{i}$ & CF & $k_{i}$ & Cakravāla & $k_{i}$ \\
\hline 1 & & 1 & & 1 & & 1 & & 1 \\
\hline 2 & $\frac{9}{1}$ & 16 & & & $\frac{7}{1}$ & 1 & & \\
\hline 3 & $\frac{10}{1}$ & 3 & $\frac{10}{1}$ & 3 & $\frac{8}{1}$ & 12 & $\frac{8}{1}$ & 3 \\
\hline 4 & $\frac{59}{6}$ & 11 & & & $\frac{39}{5}$ & 3 & $\frac{39}{5}$ & -4 \\
\hline 5 & $\frac{69}{7}$ & 8 & $\frac{69}{7}$ & 8 & $\frac{125}{16}$ & 4 & & \\
\hline
\end{tabular}


American Research Journal of Mathematics, Volume 1, Issue 4, 2015

ISSN 2378-704X

\begin{tabular}{|l|l|l|l|l|l|l|l|l|}
\hline 6 & $\frac{197}{20}$ & 9 & $\frac{197}{20}$ & 9 & $\frac{453}{58}$ & 5 & \\
\hline 7 & $\frac{325}{33}$ & 8 & & & $\frac{1070}{135}$ & 5 & \\
\hline 8 & $\frac{522}{53}$ & 11 & $\frac{325}{33}$ & 11 & $\frac{1523}{195}$ & 9 & $\frac{1523}{195}$ & 4 \\
\hline 9 & $\frac{847}{86}$ & 3 & $\frac{847}{86}$ & -3 & $\frac{5639}{722}$ & 4 & & \\
\hline 10 & $\frac{4757}{483}$ & 16 & & & $\frac{24079}{3083}$ & 3 & & $\frac{29718}{3807}$ \\
\hline 11 & $\frac{5604}{569}$ & 1 & $\frac{5604}{569}$ & -1 & $\frac{29718}{3807}$ & 12 & 4 \\
\hline
\end{tabular}

$\sqrt{97}=\left[9: 1^{*}, 5,1,1,1,1,1,1,5,1,18^{*}\right]$

$\sqrt{61}=\left[7: 1^{*}, 4,3,1,2,2,1,3,4,1,14^{*}\right]$

2.9. Rule for Forming Triangle with Consecutive Sides $x-1, x, x+1$

GK Rule 118 Ch. IV [11]:

"Divide twice an optional number by 'the square of the optional number less 3'. Add 1 to thrice the square (of the quotient). Twice the square-root of the sum is the base. 1 added to and subtracted from (the base) are the flank sides".

That is if $n$ is optional number then by equating altitude of two triangles formed from juxtaposition of two rectangles as shown in Figure-1.

Base, $x=2\left(3 y^{2}+1\right)^{1 / 2}$, i.e. indeterminate equation in $x$ and $y$ so generated is

$\frac{3}{4} x^{2}-3=y^{2}$.

Upright (altitude), $y=\frac{2 n}{n^{2}-3}$.

Flank (lateral) sides are $x \pm 1$.

In (11) kșepa (c) is considered negative.

\subsection{Method for Finding the Integral Solutions (Triangles)}

GK Rule 119-120 Ch. IV [11]:

" 3 being the length of the perpendicular and 4 , the base of the first right-angled triangle, and infinite (pairs of) rightangled triangles are produced in which sides increase by unity. (In these), the perpendicular from the vertex to the respective base is the sum of 'thrice theprevious base added to the still previous perpendicular' and the base is twice the sum of 'the previous perpendicular added to the previous base'. Triangles on opposition (in such triangles) are right-angled and in all such triangles, 1 added to and subtracted from the base, are the flank sides".

Lemma 6. Let $x=\left\{b_{n}\right\}$ be the bases, $\left\{a_{n}\right\}$ and $\left\{c_{n}\right\}$ the flank sides and $y=\left\{p_{n}\right\}$ the perpendiculars from the vertices of such triangles to the respective bases. Given that for first right-angled triangle $a_{1}=3, b_{1}=4$. The satisfying conditions (recurrence relations) are:

$b_{n}=2\left(p_{n-1}+b_{n-1}\right)$

$p_{n}=3 b_{n-1}+p_{n-2}$

and 
$a_{n}=b_{n}+1$

$c_{n}=b_{n}-1$

$(4,3)$ is a solution of $(11)$ and that $(2,2)$ of

$$
\frac{3}{4} x^{2}+1=y^{2}
$$

Herein kșepa $(c)$ is positive and is 1 .

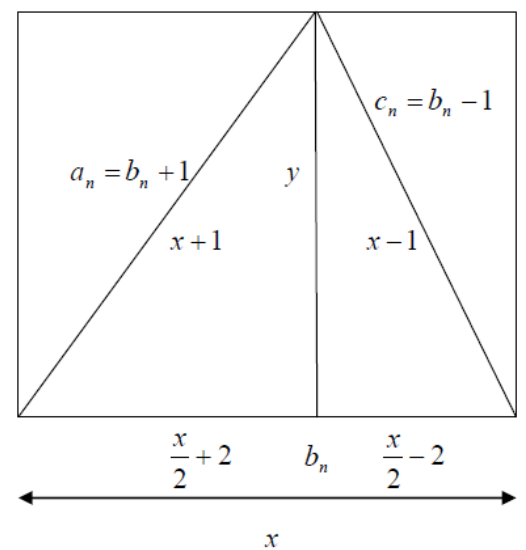

Fig1. Arithmetic triangle

Applying Samāsa Bhāvanā in equations (11) \& (14),

$b_{2}=2\left(p_{1}+b_{1}\right)$

$p_{2}=2\left(\frac{3}{4} b_{1}+p_{1}\right)$

is a solution of (11).

In general,

$b_{n}=2\left(p_{n-1}+b_{n-1}\right)$

$p_{n}=2\left(\frac{3}{4} b_{n-1}+p_{n-1}\right)$

For rationale of recurrence relations (12), refer to Singh [10, p.56].

Eliminating $b_{n-1}$ and $p_{n-1}$ from above two

$\frac{3}{4} b_{n}=p_{n}-\frac{1}{2} p_{n-1}$

$p_{n}=b_{n}-\frac{1}{2} b_{n-1}$

Making use in (12) and (13)

$b_{n}=2\left(p_{n-1}+b_{n-1}\right)=4 b_{n-1}-b_{n-2}$

$p_{n}=3 b_{n-1}+p_{n-2}=4 p_{n-1}-p_{n-2}$

Starting with $\left(b_{0}, p_{0}\right)=(2,0)$ and $\left(b_{1}, p_{1}\right)=(4,3)$, we find $\left(b_{2}, p_{2}\right)=(14,12)$. First eight such integral triplets $\left(c_{n}, b_{n}, a_{n}\right)$ are given in tabulated form 
American Research Journal of Mathematics, Volume 1, Issue 4, 2015

ISSN 2378-704X

Table6. Simulation Result

\begin{tabular}{|l|l|l|l|l|}
\hline$n$ & $p_{n}$ & $b_{n}$ & $c_{n}$ & $a_{n}$ \\
\hline 1 & 3 & 4 & 3 & 5 \\
\hline 2 & 12 & 14 & 13 & 15 \\
\hline 3 & 45 & 52 & 51 & 53 \\
\hline 4 & 168 & 194 & 193 & 195 \\
\hline 5 & 627 & 724 & 723 & 725 \\
\hline 6 & 2340 & 2702 & 2701 & 2703 \\
\hline 7 & 8733 & 10084 & 10083 & 10085 \\
\hline 8 & 32592 & 37624 & 37613 & 37615 \\
\hline
\end{tabular}

Example4 GK 90. If you have pride in geometry, tell the triangles in which sides increase by unity, in many ways.

Theorem3 (Generalization). If $(x-d, x, x+d)$ are the integral triplets, then

$(x-d)^{2}-\left(\frac{x}{2}-2 d\right)^{2}=y^{2}$, i.e. $\frac{3}{4} X^{2}-3=Y^{2}$,

where $X=\frac{x}{d}, Y=\frac{y}{d}$.

Thus $d\left(b_{n}, p_{n}\right)$ is a solution of resulting equation (17).

\subsection{Brahmagupta Triangles}

Beauregard-Suryanarayan [13] makes use of the formula for area of the triangle $\Delta=\sqrt{s(s-a)(s-b)(s-c)}$, where $s=(a+b+c) / 2$ semi-perimeter of triangle having sides a,b,c. For triangle with integer sides $t-1, t, t+1, s=\frac{3 t}{2}$ and $\Delta=\frac{t}{2} \sqrt{3\left(\frac{t}{2}\right)^{2}-1}$ (see Figure-2). Assuming $t=2 X$, we have $\Delta^{2}=3\left(X^{2}-1\right)$. Further, area of triangle with altitude $l, \Delta=\frac{1}{2} 2 X . l=X l$. This implies $l^{2}=3\left(X^{2}-1\right)$ is an integer. So let $l=3 Y$. The equation (11) reduces to

$3 Y^{2}+1=X^{2}$.

The initial solutions are $(0,1)$ and $(1,2)$. Thereby using Samāsa Bhāvanā,

$p_{n}=b_{n-1}+2 p_{n-1}$

$b_{n}=3 p_{n-1}+2 b_{n-1}$

Eliminating $p_{n-1}$ and $b_{n-1}$ from above two

$3 p_{n}=2 b_{n}-b_{n-1}$

$b_{n}=2 p_{n}-p_{n-1}$

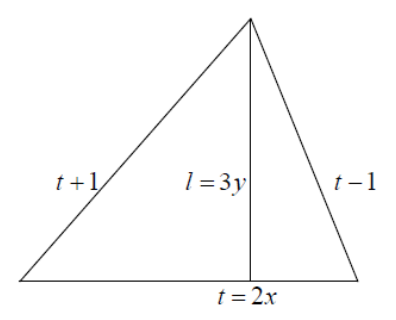

Fig2. Arithmetic triangle 
Making use of these in (19) and (20)

$p_{n}=4 p_{n-1}-p_{n-2}$

$b_{n}=4 b_{n-1}-b_{n-2}$

The solutions are $(Y, X)=\left(3 p_{n}, 2 b_{n}\right)$. Eight integral triangles given by Brahmagupta are

as:(3,4,5),(13,14,15),(51,52,53),(193,194,195),(723,724,725),

$(2701,2702,2703),(10083,10084,10085),(37633,37634,37635)$.

Hoppe (1879) and Aubry (1911) are reported to work on similar aspects [13].

Bhāskara I makes use of scalene triangle $(13,14,15)$ with half of base $14 / 2=7$. The triangle was deformed into a rectangle with length 12 and breadth 7, that is, of area 84. Alternatively he transformed the triangle into two rectangles with sides 12,5 and 12,9 [7]. Heron of Alexandria (c. 75 AD) provided an illustration of a triangle with sides $13,14,15$ and area 84

\subsection{Varga Prakrti with Negative Interpolator}

Marici Commentary on Jyotpatti v. 21-25 of Muniśvara (c. 1638AD) gives the relation

$$
-(R \sin \theta)^{2}+R^{2}=(R \cos \theta)^{2}
$$

Herein $N=-1, k=R^{2}, x=R \sin \theta, y=R \cos \theta$.

Let $\left(x_{1}, y_{1}\right)=(R \sin \alpha, R \cos \alpha),\left(x_{2}, y_{2}\right)=(R \sin \beta, R \cos \beta)$. Samāsa Bhāvanā is applied to get some sort of additive solutions $(x, y)$ for sine and cosine functions of $-x^{2}+R^{4}=y^{2}$, i.e. $-\left(\frac{x}{R}\right)^{2}+R^{2}=\left(\frac{y}{R}\right)^{2}$,

$$
\begin{aligned}
& x=R^{2}(\sin \alpha \cos \beta+\cos \alpha \sin \beta) \\
& y=R^{2}(\cos \alpha \cos \beta-\sin \alpha \sin \beta)
\end{aligned}
$$

On the similar line of Antra Bhāvanāthe corresponding solution to (23) are

$$
\begin{aligned}
& x=R^{2}(\sin \alpha \cos \beta-\cos \alpha \sin \beta) \\
& y=R^{2}(\cos \alpha \cos \beta+\sin \alpha \sin \beta)
\end{aligned}
$$

Siddhāntasarva Bhāvanā II,v.58-59 v. 21-25 of Muniśvara also gives the derivation of the theorems.

In modern equivalent if $\left(x_{1}, y_{1}\right)=(\sin \alpha, \cos \alpha),\left(x_{2}, y_{2}\right)=(\sin \beta, \cos \beta)$ are solutions of $-x^{2}+R^{2}=y^{2}$, then so also $x=\sin (\alpha \pm \beta), y=\cos (\alpha \pm \beta)$.

\section{Examples}

1 Bhāskara II $-5 x^{2}+21=y^{2}$. Solutions by trial: $(1,4),(2,1)$

2 Nārāyana $-11 x^{2}+60=y^{2}$. Solutions by trial: $(1,7),(2,4)$

2.13. Nārāyaṇa Matrix Equivalent Method for $N x^{2}+c=y^{2}$

We make use of GK Rule 15-16. If $(a, b)$ is a solution of $N x^{2}+c=y^{2}$ and $(p, q)$ of $N x^{2} \pm 1=y^{2}$, then by the principle of composition $(b p \pm a q, b p \pm N a p)$ will be the solution of $N x^{2} \pm c=y^{2}$.

Define [13] $U(a, b)=\left[\begin{array}{ll}b & a \\ N a & b\end{array}\right], \operatorname{det} U=c$ and $V(p, q)=\left[\begin{array}{ll}q & p \\ N p & q\end{array}\right], \operatorname{det} V=1$.

$U(a, b) V(p, q)=\left[\begin{array}{lc}b & a \\ N a & b\end{array}\right]\left[\begin{array}{ll}q & p \\ N p & q\end{array}\right]=\left[\begin{array}{lc}b q+N a p & b p+a q \\ N(b p+a q) & b q+N a p\end{array}\right]=W(b p+a q, b q+N a p)$ 


$$
\begin{aligned}
\operatorname{det} W= & (b q+N a p)^{2}-N(b p+a q)^{2}=N^{2} a^{2} p^{2}+b^{2} q^{2}-N a^{2} q^{2}-N b^{2} p^{2} \\
& =\left(b^{2}-N a^{2}\right)\left(q^{2}-N p^{2}\right)=c \cdot 1=\operatorname{det} U \cdot \operatorname{det} V=\operatorname{det} U V .
\end{aligned}
$$

Let $a=x_{0}, b=y_{0}, p=x_{n-1}, q=y_{n-1}$. The rest of the solutions $(x, y)$ are governed by

$$
x_{n}=y_{0} x_{n-1}+x_{0} y_{n-1}, y_{n}=y_{0} y_{n-1}+N x_{0} x_{n-1}
$$

$\left[\begin{array}{l}x_{n} \\ y_{n}\end{array}\right]=\left[\begin{array}{cc}y_{0} & x_{0} \\ N x_{0} & y_{0}\end{array}\right]\left[\begin{array}{l}x_{n-1} \\ y_{n-1}\end{array}\right]$

$X_{n}=U X_{n-1}=\lambda X_{n-1}$, say

$\operatorname{det}[U-\lambda I]=0$, i.e. $\operatorname{det}\left[\begin{array}{ll}y_{0}-\lambda & x_{0} \\ N x_{0} & y_{0}-\lambda\end{array}\right]=0$.

This gives $\lambda_{1}=y_{0}+\sqrt{N} x_{0}, \lambda_{2}=y_{0}-\sqrt{N} x_{0}$

The corresponding eigen vectors are $X_{1 n}=\left[\begin{array}{l}\sqrt{N} \\ 1\end{array}\right], X_{2 n}=\left[\begin{array}{l}-\sqrt{N} \\ 1\end{array}\right]$.

$D=P^{-1} U P=\left[\begin{array}{ll}\lambda_{1} & 0 \\ 0 & \lambda_{2}\end{array}\right], \lambda_{1} \lambda_{2}=c$.

$\left[\begin{array}{l}x_{n} \\ y_{n}\end{array}\right]=\left[\begin{array}{ll}\lambda_{1} & 0 \\ 0 & \lambda_{2}\end{array}\right]\left[\begin{array}{l}x_{n-1} \\ y_{n-1}\end{array}\right]$

$x_{n}=\lambda_{1} x_{n-1}=\lambda_{1}^{n} x_{0}$

$y_{n}=\lambda_{2} x_{n-1}=\lambda_{2}^{n} y_{0}$

Using $x_{0}=\frac{\lambda_{1}-\lambda_{2}}{2 \sqrt{N}}, y_{0}=\frac{\lambda_{1}+\lambda_{2}}{2}$.

\subsection{Application}

Here we cite an example from Büjagaṇita of Bhāskara II [v. 159; 16, pp. 154-155].

For the arithmetic progression (AP) with first term 3 and common difference 2, find $m$ and $n$ such that $S_{m}=3 S_{n}$, where $S_{r}$ the sum of first $\mathrm{r}$ is terms of AP.

From $S_{m}=3 S_{n}, \frac{m}{2}[6+2(m-1)]=\frac{3 n}{2}[6+2(n-1)]$. This implies

$m^{2}+2 m-\left(3 n^{2}+6 n\right)=0$, i.e.

$m=-1+\sqrt{3 n^{2}+6 n+1}$.

Let $3 n^{2}+6 n+1=z^{2}$. Putting $n=t-1$, we find $3 t^{2}-2=z^{2}$.

By trial $3.1^{2}-2=1^{2}$ and $3.1^{2}+1=2^{2}$.

By additive composition $3.3^{2}-2=5^{2}$.

By applying composition twice we get other two solutions. Thus $(t, z)=(3,5),(11,19),(41,71)$ are the solutions of (23). Hence $n=2,10,40$ and $m=-1+5,-1+19,-1+71$, i.e. $4,18,70$. 


\section{REFERENCES}

[1] AK Bag, The Method of Integral Solution of Indeterminate Equations of the Type: $B y=A x \pm C$ in Ancient and Medieval India, Indian Journal of History of Science 12 (1977), 1-16.

[2] B Datta and AN Singh, History of Hindu Mathematics, Two Parts, Asia Publishing House, Bombay, 1962.

[3] C.B. Boyer, A History of Mathematics (revised by Uta C. Merzbach), John Wiley \& Sons, New York, 1989.

[4] Clas-Ol of Selenius, Rationale of Cakravala Process of Jayadeva and Bhāskara II, Historia Mathematika 2 (1975), 167184.

[5] K.S. Shukla and K.V. Sarma, Arryabhatīya of Āryabhața I, Indian National Science Academy, New Delhi, 1976.

[6] KS Patwardhan, SA Naimpally and SL Singh, Līlāvatī of Bhāskarācāyra: A Treatise on Mathematics of Vedic Tradition, Motilal Banarsidass, 2001.

[7] NL Maiti, On the Principal of Verification in Ancient Indian Mathematics, Ganita Bhāratĩ24 (2002), 99 -104.

[8] Parmanand Singh, The Ganitakaumudī of Nārāyana Paṇdita (Translation with Notes), Chapters V-XII, Ganita Bhāratī 22(2000), 19-85.

[9] Parmanand Singh, The Gaṇitakaumudī of Nārāyana Paṇdita. (translation with notes), Gaṇita Bhāratī 20 (1998), 25 - 82.

[10] Parmanand Singh, The Ganitakaumudī of Nārāyana Paṇdita. (translation with notes), Chapter IV,Ganita Bhāratĩ 21 (1999), $10-73$.

[11] Parmanand Singh, Varga-prakrty-the Cakravala Method of its Solution and the Regular Continued -Fractions, Indian Journal of History of Science 19 (1983), 1-17.

[12] PK Majumdar, Gaṇita Kaumudī and Continued Fraction, Indian Journal of History of Science 1978, 1-4.

[13] R.A. Beauregard and E.R. Suryanarayan, The Brahmagupta Triangles, The College Mathematics Journal 29 (1998), 13-17.

[14] R.S. Sharma, Brahmsphuțasiddhānta, Vol. I, Indian Institute of Astronomical and Sanskrit Research, New Delhi, 1966.

[15] SB Rao, Indian Mathematics and Astronomy: Some Landmarks, Bhartiya Vidya Bhavan, 2004.

[16] TB Hardikar, Indeterminate Analysis, 1991.

[17] TS Bhanu Murthy, A Modern Introduction to ancient Indian Mathematics, Wiley Eastern Ltd, 1993.

[18] Vinod Mishra, Computing $\sqrt{N}$ : A Modern Generalization of Ancient Technique, Indian Journal of History of Science 46 (2011), 49-61. 